University of Nebraska - Lincoln

DigitalCommons@University of Nebraska - Lincoln

\title{
An examination of ethical attitudes towards wild pig (Sus scrofa) toxicants in the United States
}

Keith Carlisle

Erin E. Harper

Stephanie A. Shwiff

Follow this and additional works at: https://digitalcommons.unl.edu/icwdm_usdanwrc

Part of the Natural Resources and Conservation Commons, Natural Resources Management and Policy Commons, Other Environmental Sciences Commons, Other Veterinary Medicine Commons, Population Biology Commons, Terrestrial and Aquatic Ecology Commons, Veterinary Infectious Diseases Commons, Veterinary Microbiology and Immunobiology Commons, Veterinary Preventive Medicine, Epidemiology, and Public Health Commons, and the Zoology Commons

This Article is brought to you for free and open access by the U.S. Department of Agriculture: Animal and Plant Health Inspection Service at DigitalCommons@University of Nebraska - Lincoln. It has been accepted for inclusion in USDA Wildlife Services - Staff Publications by an authorized administrator of DigitalCommons@University of Nebraska - Lincoln. 


\title{
An examination of ethical attitudes towards wild pig (Sus scrofa) toxicants in the United States
}

\author{
Keith M. Carlisle ${ }^{a, b}$ (D) Erin E. Harper ${ }^{b}$ and Stephanie A. Shwiff ${ }^{b}$ \\ a Department of Human Dimensions of Natural Resources, Warner College of Natural Resources, Colorado State University, Fort \\ Collins, CO, USA; ${ }^{b}$ National Wildlife Research Center, United States Department of Agriculture, Animal and Plant Health \\ Inspection Service, Fort Collins, CO, USA
}

\begin{abstract}
This research aims to understand ethical attitudes of the U.S. public towards the use of a toxicant to control wild pigs (Sus scrofa), a destructive invasive species whose population growth is proving difficult to control through conventional management methods. Using a nationwide self-administered survey with 2,186 completed and returned questionnaires, we found that among six different lethal control methods, toxicant usage was the only method that a majority of respondents (51\%) found to be unethical, with no significant differences between rural and urban respondents or between respondents from counties with wild pigs and counties where the species is absent. The primary concerns of respondents were collateral harm to other animals (33\%) and possible pain and suffering of wild pigs (13\%). This research suggests that the introduction of a wild pig toxicant in the U.S. could face significant opposition, particularly if the public's concerns highlighted in this study are not well understood and addressed in product development and outreach.
\end{abstract}

\section{ARTICLE HISTORY}

Received 2 April 2020

Accepted 29 June 2020

\section{KEYWORDS}

Poison; Sus scrofa; feral pigs; ethical attitudes; invasive spe-

cies management

\section{Introduction}

Wild pigs (Sus scrofa), also known as feral swine, feral hogs, wild hogs, and wild boar (Keiter et al. 2016), are an invasive, non-native species in the United States. They wreak considerable damage on crops, livestock, and infrastructure; degrade water quality and wildlife habitat; and carry the risk of disease transmission to humans and other animals (Harper et al. 2016; Caplenor et al. 2017). By one estimate, they account for at least $\$ 1.5$ billion in crop losses and control efforts each year in the United States (Pimentel 2007), though that estimate may be low with inflation and the continued expansion of wild pig populations in the decade since the study was published. With their adaptability and high fecundity, wild pigs may be capable of doubling their numbers in an area in as little as one year, and as much as $90 \%$ of a population may have to be removed to yield a significant decline in their rate of population growth (Caplenor et al. 2017). This is a challenging task for landowners and wildlife managers who typically employ or authorize hunting and trapping to reduce wild pig numbers. In most states, efforts to eradicate wild pigs or halt their expansion have met with limited success. Between 1982 and 2016, the number of U.S. states that reported wild pig populations increased from
18 to 35 , with the geographic area of wild pig distribution nearly tripling from $544,854 \mathrm{~km}^{2}$ to $1,675,618 \mathrm{~km}^{2}$ during the same period (Corn and Jordan 2017).

The management challenges presented by wild pigs has left resource managers searching for more effective tools to control population numbers, with toxicants receiving serious consideration in states with high wild pig population densities. In Texas, where wild pigs are responsible for extensive agricultural damage (Anderson et al. 2016), the state's Agriculture Commissioner issued an emergency rule in 2017 that approved limited use of a warfarinbased wild pig toxicant marketed as Kaput ${ }^{\circledR}$ Feral Hog Bait (Kaput) (Poché et al. 2018). This action was met with a swift backlash that included a lawsuit initiated by a wild pig meat processor and lobbying efforts carried out by a diverse coalition of hunting, animal welfare, and environmental interests. Roughly four months later, the manufacturer of Kaput withdrew its registration of the toxicant in Texas, citing concern over litigation costs. At this time, no wild pig toxicants are being used in any U.S. state, though Kaput remains federally registered and efforts are underway to develop a sodium nitrite-based wild pig toxicant (branded HOGGONE() for use in the United States and Australia (Snow et al. 2018). As illustrated by the attempted

CONTACT Keith M. Carlisle keith.carlisle@colostate.edu Warner College of Natural Resources Colorado State University 1401 Campus Delivery Fort Collins, CO 80523 USA

(C) 2020 Informa UK Limited, trading as Taylor \& Francis Group 
introduction of Kaput in Texas, however, the proposed use of a wild pig toxicant may generate considerable opposition, particularly if the public's concerns are not well understood and addressed prior to introduction.

\section{Research objectives}

The objectives of this study were (i) to measure and compare ethical attitudes of the U.S. public in rural and urban counties, and in counties where pigs are present and those where they are absent, concerning the use of toxicants as compared to other lethal methods to control wild pig populations; (ii) to understand the reasons why members of the aforementioned subpopulations may support or oppose the use of toxicants on wild pigs; and (iii) to consider the implications of our findings for efforts to control wild pig populations through the use of a toxicant. We focused on ethical attitudes - i.e., judgments about whether something is morally right or wrong (Vänninen et al. 2009) - because there is evidence that ethical or moral considerations are an important predictor of a person's ultimate support of, or opposition to, a particular policy or practice (Tanaka 2004; Sjöberg 2008). Our rationale for comparing ethical attitudes in counties that have, or previously had, wild pigs with those unaffected by wild pigs was to understand whether proximity to, or familiarity with, wild pigs may be associated with greater support for the use of toxicants. Similarly, as rural areas may be more dependent on agriculture and therefore potentially more vulnerable to damage from wild pigs, our rationale for comparing attitudes in rural areas to those in urban areas was to understand whether such vulnerability may be associated with greater support for the use of toxicants. Additionally, information about any significant differences between attitudes of rural and urban populations concerning lethal control of wild pigs could help to inform more contextually-tailored and acceptable wild pig management strategies in rural and urban areas. We also note that as most US counties could be inhabited by wild pigs in the next three-to-five decades based upon recent modeling (Snow et al. 2017), an understanding of attitudes towards the use of toxicants and other control methods in areas presently lacking wild pigs is important for purposes of planning for the likely spread of wild pigs in the future.

\section{Methods}

Data concerning ethical attitudes towards lethal control of wild pigs were collected using a mixed-mode, nationwide survey based upon a modified Dillman design (Dillman et al. 2014). The commercial data vendor InfoUSA ${ }^{\circledR}$ provided the sample, which was stratified to include 200 residents of rural areas and 200 residents of urban areas in each of the 50 states to ensure adequate representation in our sample of the subpopulations of interest in this study. A prenotification postcard was mailed to the 20,000 individuals in the sample in January, 2017, followed one week later by a packet that included a cover letter, questionnaire, and a stamped return envelope. Two weeks later, a thank you/reminder postcard was mailed to the sample, followed by a second questionnaire packet three weeks later. A final thank you/reminder post card with an online response option was mailed to the sample eight weeks after the second questionnaire packet was mailed. The online questionnaire was provided through SurveyMonkey®.

The questionnaire included items for several studies, and it was divided into the following three sections: (i) beliefs about and interactions with wildlife; (ii) knowledge and beliefs about wild pigs and wild pig control methods; and (iii) demographics. This study utilized data collected from sections two and three of the questionnaire. Among other things, section two measured beliefs about the ethicality of various wild pig lethal control methods by asking participants to state how much they agree or disagree with five statements using a seven-point Likert-like scale, with 1 corresponding to "strongly disagree" that a particular method is ethical, 4 corresponding to "neutral," and 7 corresponding to "strongly agree" that the method is ethical. The wording of these statements was informed by a substantially similar questionnaire developed by the second author that was orally administered in Southeastern states in 2016. For the statement concerning the use of a toxicant, we chose to use the term 'poison' because we believed it would be better understood by the lay public than 'toxicant' based upon feedback received during the development phase of the 2016 study. All the statements were identical in all questionnaires, with the exception that half the sample was randomly assigned a version of the questionnaire in which the wording of one statement was modified in order to test the impact of wording on responses. Specifically, the statement 'Trapping and removing wild pigs is ethical,' was modified in half of the questionnaires to read 'Trapping and lethally removing wild pigs is ethical.' To obtain additional data about participants' attitudes and beliefs towards the use of a wild pig toxicant, an open-ended question was included in the questionnaire in which respondents were asked to provide more information about their 
Table 1. Themes used in coding open-ended question concerning the use of a wild pig poison.

\begin{tabular}{|c|c|}
\hline Theme & Explanation \\
\hline 1: Impacts on humans & $\begin{array}{l}\text { Respondent expresses concern about possible harm to humans, including the tainting of pig meat that } \\
\text { could be used for human consumption or the accidental consumption of poison by children }\end{array}$ \\
\hline 2: Impacts on non-target animals & $\begin{array}{l}\text { Respondent expresses concern about unintended consequences for wildlife and/or domesticated } \\
\text { animals, including pets }\end{array}$ \\
\hline 3: Environmental impacts & $\begin{array}{l}\text { Respondent expresses concern about possible harm to the environment and/or particular } \\
\text { environmental components (e.g., soil, water) }\end{array}$ \\
\hline 4: Cruelty to pigs & Respondent expresses concern that poison is cruel or may cause suffering for pigs \\
\hline 5: Support as last resort & $\begin{array}{l}\text { Respondent indicates that he/she prefers other methods over poison and/or supports poison only if } \\
\text { other methods prove insufficient }\end{array}$ \\
\hline 6: Prefer poison & $\begin{array}{l}\text { Respondent indicates that he/she prefers poison over other methods and/or that poison is the most } \\
\text { effective or best way to control wild pigs }\end{array}$ \\
\hline 7: General opposition & $\begin{array}{l}\text { Respondent expresses non-specific concern or opposition to the use of poison (e.g., 'I don't believe } \\
\text { poison is ever a good idea') }\end{array}$ \\
\hline 8: General support & $\begin{array}{l}\text { Respondent expresses non-specific support for the use of poison (e.g., 'We have to use poison in order } \\
\text { to stop the spread of wild pigs') }\end{array}$ \\
\hline
\end{tabular}

support or opposition to the use of poison to kill wild pigs.

In section three of the questionnaire, respondents were asked to report their gender, age, race, education level, income, and state and county of residence. We matched reported counties with publicly available U.S. Census Bureau rural/urban county classification data (U.S. Census Bureau 2010) to facilitate analysis and comparison on this basis. We also matched county data with data developed and maintained by the Animal and Plant Health Inspection Service, U.S. Department of Agriculture, that identifies counties where wild pigs are present or have been sighted (Lutman 2017). Doing so allowed us to analyze and compare survey data on the basis of a respondent's proximity to wild pigs.

Out of the 20,000 mailed surveys, 2,213 were returned for a response rate of $11 \%$. However, 27 returned questionnaires were excluded from our analysis because they were incomplete. Of the remaining 2,186 returned questionnaires, 1,094 were from urban counties and 1,092 were from rural counties, while 690 were from counties with wild pigs and 1,496 were from counties with no wild pigs. In addition, 1,076 of the returned questionnaires were of the version one type ('Trapping and removing wild pigs is ethical') and 1,110 were of the version two type ('Trapping and lethally removing wild pigs is ethical').

Although the response rate was lower than anticipated, our completed sample size well exceeded the minimum required to be generalizable to the entire U.S. public $(n=384)$ and to each subpopulation of interest, calculated pursuant to Cochran's sample size formula (Cochran 1977; Bartlett et al. 2001). The required sample size for the entire U.S. population was calculated based upon a U.S. population of 325.7 million people, a 95\% confidence level, and a $5 \%$ margin of error. While certain demographic characteristics of our completed sample were similar to those of the U.S. population (e.g., the median household income of respondents fell within the response category $\$ 50,000$ to $\$ 74,999$ compared to a median household income in the U.S. population of $\$ 55,322)$, others were overrepresented. For example, $56 \%$ of respondents were male compared to $49 \%$ in the general population, and $86 \%$ of respondents were white compared to $77 \%$ in the general population (U.S. Census Bureau 2017).

All questionnaire data were entered into a Microsoft Excel spreadsheet, and descriptive statistics were generated in the program. Statistical comparisons of responses to the lethal control belief statements were made between subgroups by performing Wilcoxon rank sum tests because the data was nonparametric and non-normally distributed (Bridge and Sawilowsky 1999). These tests were performed using $\mathrm{R}$ statistical software (R Development Core Team 2018). Qualitative data from the openended question concerning the use of poison were analyzed and coded in Microsoft Excel for eight a priori themes (Table 1). While four of the themes represent support or opposition to the use of poison for wild pig control ('general opposition,' 'general support,' 'support as last resort,' and 'prefer poison,'), the remaining four themes reflect categories of concern ('impacts on humans,' 'impacts on nontarget animals,' 'environmental impacts,' and 'cruelty to pigs'), and should not be interpreted as necessarily indicative of opposition to toxicant usage. For example, if a respondent wrote that he/she supports a toxicant so long as it does not cause wild pigs to have a painful death, the response would have been coded to the theme 'cruelty to pigs.' Two trained coders coded the data after first conducting a coding reliability check on $15 \%$ of the responses to ensure substantial agreement between the coders on the interpretation and coding of responses. Doing so yielded a generally acceptable reliability coefficient of 0.83 (i.e., $83 \%$ agreement) (Neuendorf 2002). None of the themes were coded more than once per response, but for some responses, multiple (different) themes were present and coded. After all responses were coded, chi-square tests were 


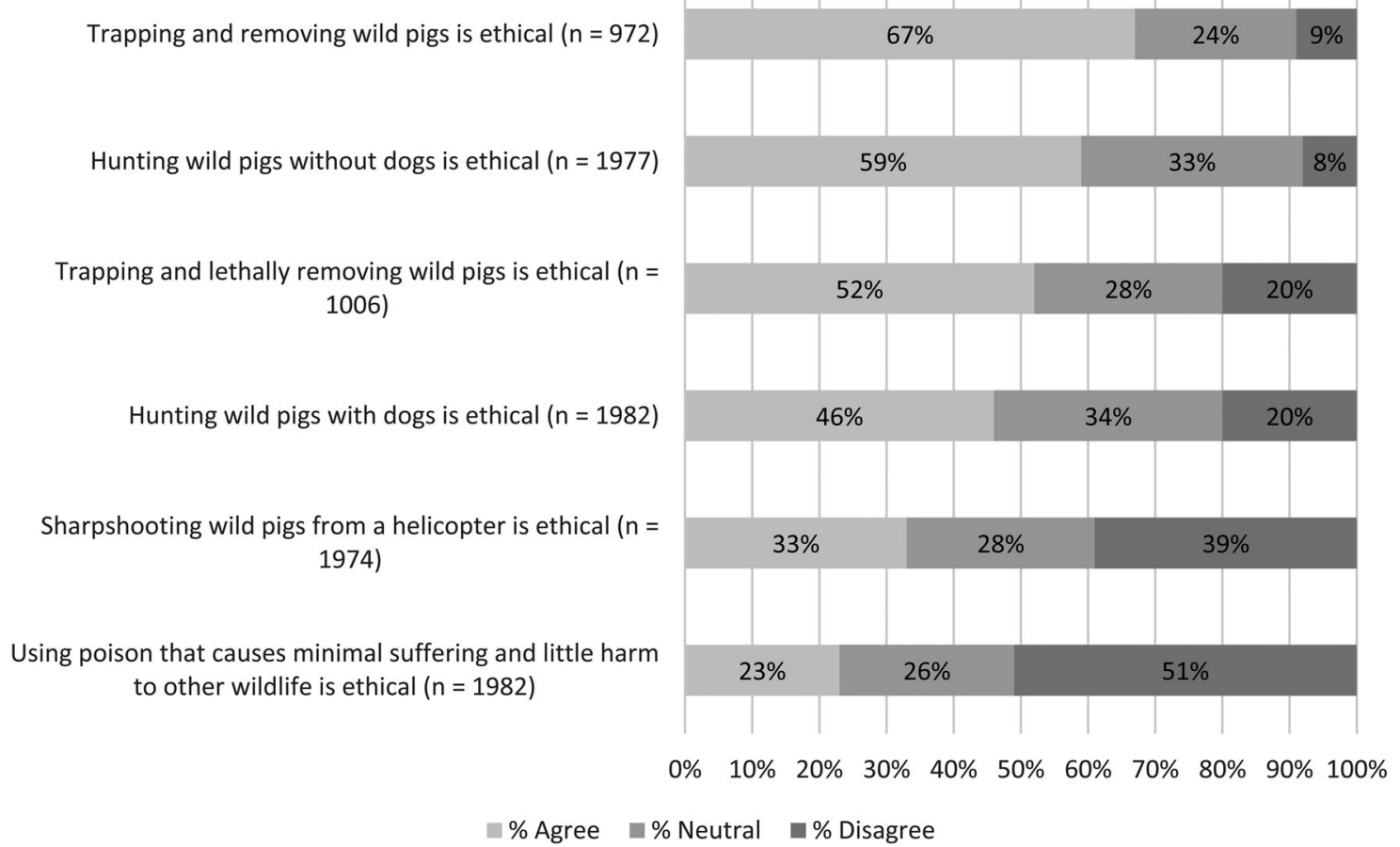

Figure 1. Overall percentage agreement with lethal control belief statements (all respondents).

performed in Excel to compare the occurrence proportion (percent) of themes among the subgroups of interest.

\section{Results}

\section{Responses to belief statements}

Among the six belief statements, agreement was highest with the statement 'Trapping and removing wild pigs is ethical,' with $67 \%$ agreeing with the statement, 9\% disagreeing, and 24\% responding 'neutral' (Figure 1). In addition, a majority of respondents either agreed or were neutral with respect to all of the belief statements except for the statement concerning the use of poison. The statement 'Using poison that causes minimal suffering and little harm to other wildlife is ethical' was the only statement with which a majority of respondents (51\%) disagreed. We also found that the level of agreement with the statement 'Trapping and lethally removing wild pigs' was 15 percentage points lower than the level of agreement with the version of the same statement that excluded the word 'lethally' (Wilcoxon rank sum: $\mathrm{p}<.001$ ).

In comparing mean response scores of rural county residents to urban county residents, and of residents of counties with wild pigs to residents of counties with no wild pigs, we found statistically significant differences in responses to all of the belief statements except for the statement concerning the use of poison (Table 2). The mean response score to the poison statement for respondents from counties with wild pigs was 3.30 compared to 3.28 for respondents from counties with no wild pigs (Wilcoxon rank sum: $p=0.908$ ), while the mean score for urban respondents was 3.26 compared to 3.32 for rural respondents (Wilcoxon rank sum: $\mathrm{p}=0.673$ ).

\section{Responses to open-ended question}

We received 1,207 write-in responses $(54.5 \%$ of respondents) to the question asking for information about the respondent's support of or opposition to the use of a poison on wild pigs. Of these, 609 were from urban counties, 598 were from rural counties, 414 were from counties with wild pigs, and 793 were from counties with no wild pigs. Among the eight themes, concern about the possible impacts of poison on non-target animals occurred most frequently $(\mathrm{n}=400)$, followed by general expressions of opposition or concern about poison $(n=226)$ (Figure 2). Among the themes that represent specific areas of concern, impacts on non-target animals was followed by cruelty to pigs $(n=153)$, environmental impacts $(n=80)$, and impacts on humans $(n=79)$.

In comparing the occurrence proportion of themes by respondent subgroups, we found no statistical differences between rural and urban respondents or between respondents from counties with wild pigs and those from counties with no wild pigs for any of the eight themes (Table 3). For example, the theme 'concern about impacts on non-target animals' occurred in $32 \%$ of responses from urban respondents and $35 \%$ of responses from rural respondents (chi-square: $p=0.443$ ). Similarly, the 
Table 2. Mean of responses to lethal control belief statements by respondent subgroup.

\begin{tabular}{|c|c|c|c|c|c|c|c|}
\hline Belief statements & $\begin{array}{c}\text { All } \\
\text { respondents }\end{array}$ & $\begin{array}{l}\text { Counties with } \\
\text { wild pigs }\end{array}$ & $\begin{array}{c}\text { Counties with } \\
\text { no wild pigs }\end{array}$ & $\begin{array}{l}\text { Wilcoxon rank } \\
\text { sum (pigs/ } \\
\text { no pigs) }\end{array}$ & $\begin{array}{c}\text { Urban } \\
\text { counties }\end{array}$ & $\begin{array}{c}\text { Rural } \\
\text { counties }\end{array}$ & $\begin{array}{c}\text { Wilcoxon rank } \\
\text { sum } \\
\text { (urban/rural) }\end{array}$ \\
\hline $\begin{array}{l}\text { Trapping and removing wild } \\
\text { pigs is ethical }\end{array}$ & 5.14 & 5.26 & 5.08 & $p<0.05$ & 5.13 & 5.15 & $p=0.584$ \\
\hline $\begin{array}{l}\text { Hunting wild pigs without } \\
\text { dogs is ethical }\end{array}$ & 5.10 & 5.25 & 5.04 & $p<0.001$ & 4.96 & 5.25 & $p<0.001$ \\
\hline $\begin{array}{l}\text { Trapping and lethally } \\
\text { removing wild pigs } \\
\text { is ethical }\end{array}$ & 4.67 & 4.96 & 4.55 & $p<0.001$ & 4.44 & 4.94 & $p<0.001$ \\
\hline $\begin{array}{l}\text { Hunting wild pigs with dogs } \\
\text { is ethical }\end{array}$ & 4.60 & 4.73 & 4.54 & $p<0.01$ & 4.48 & 4.73 & $p<0.001$ \\
\hline $\begin{array}{l}\text { Sharpshooting wild pigs } \\
\text { from a helicopter } \\
\text { is ethical }\end{array}$ & 3.90 & 4.11 & 3.81 & $p<0.01$ & 3.77 & 4.05 & $p<0.01$ \\
\hline $\begin{array}{l}\text { Using poison that causes } \\
\text { minimal suffering and } \\
\text { little harm to other } \\
\text { wildlife is ethical }\end{array}$ & 3.28 & 3.30 & 3.28 & $p=0.908$ & 3.26 & 3.32 & $p=0.673$ \\
\hline
\end{tabular}

$1=$ strongly disagree, $2=$ disagree, $3=$ somewhat disagree, $4=$ neutral, $5=$ somewhat agree, $6=$ agree, $7=$ strongly agree.

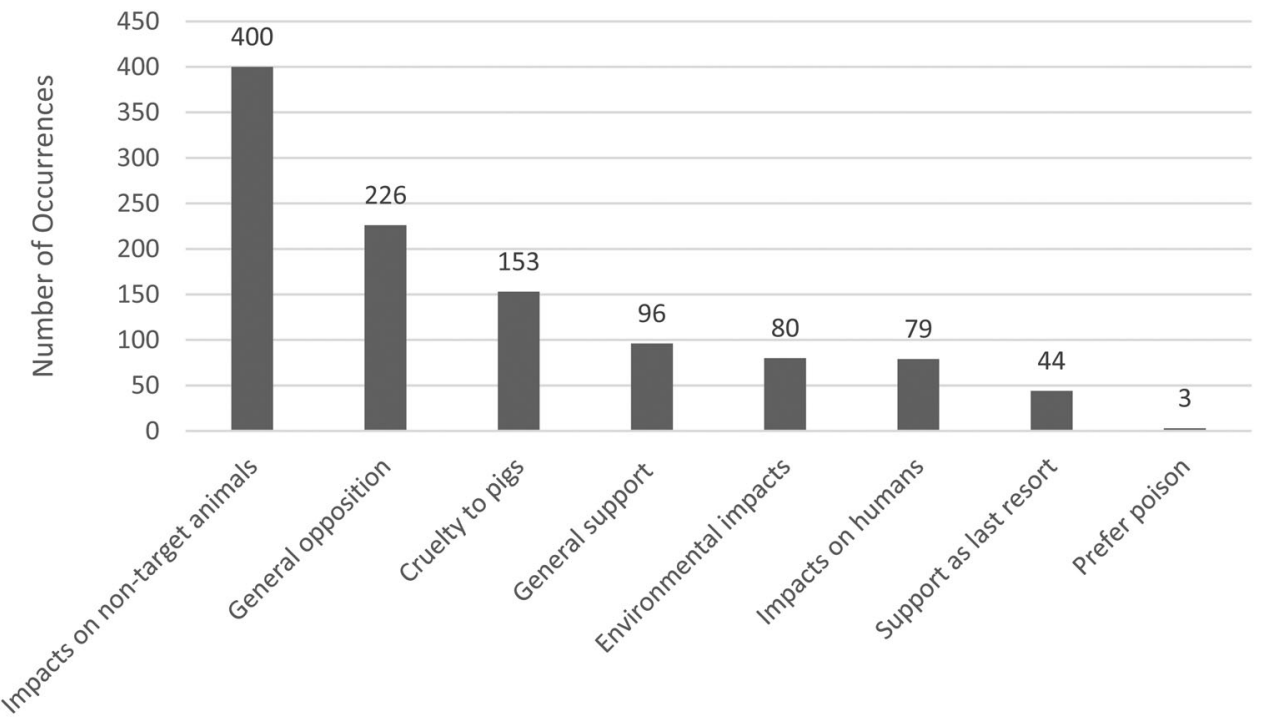

Themes

Figure 2. Frequency of theme occurrence in responses to open-ended question about wild pig poison usage.

Total number of responses $=1,207$.

Table 3. Responses to open-ended question about wild pig poison usage by respondent subgroup.

\begin{tabular}{|c|c|c|c|c|c|c|c|}
\hline Themes & $\begin{array}{c}\text { All } \\
\text { respondents }\end{array}$ & $\begin{array}{l}\text { Counties with } \\
\text { wild pigs }\end{array}$ & $\begin{array}{l}\text { Counties with } \\
\text { no wild pigs }\end{array}$ & $\begin{array}{c}\text { Chi-square } \\
\text { (pigs/no pigs) }\end{array}$ & $\begin{array}{l}\text { Urban } \\
\text { counties }\end{array}$ & $\begin{array}{c}\text { Rural } \\
\text { counties }\end{array}$ & $\begin{array}{l}\text { Chi-square } \\
\text { (urban/rural) }\end{array}$ \\
\hline $\begin{array}{l}\text { Concern about impacts on } \\
\text { non-target animals }\end{array}$ & $33 \%$ & $36 \%$ & $31 \%$ & $p=0.150$ & $32 \%$ & $35 \%$ & $p=0.443$ \\
\hline $\begin{array}{l}\text { General opposition to use of } \\
\text { poison on wild pigs }\end{array}$ & $19 \%$ & $19 \%$ & $19 \%$ & $p=0.852$ & $18 \%$ & $20 \%$ & $p=0.598$ \\
\hline $\begin{array}{l}\text { Concern about cruelty to } \\
\text { wild pigs }\end{array}$ & $13 \%$ & $13 \%$ & $12 \%$ & $p=0.822$ & $14 \%$ & $11 \%$ & $p=0.184$ \\
\hline $\begin{array}{l}\text { General support for use of } \\
\text { poison on wild pigs }\end{array}$ & $8 \%$ & $9 \%$ & $7 \%$ & $p=0.459$ & $8 \%$ & $8 \%$ & $p=0.947$ \\
\hline $\begin{array}{l}\text { Concern about } \\
\text { environmental impacts }\end{array}$ & $7 \%$ & $7 \%$ & $7 \%$ & $p=0.912$ & $7 \%$ & $6 \%$ & $p=0.665$ \\
\hline $\begin{array}{l}\text { Concern about impacts } \\
\text { on humans }\end{array}$ & $7 \%$ & $7 \%$ & $7 \%$ & $\mathrm{p}=0.985$ & $7 \%$ & $7 \%$ & $p=0.982$ \\
\hline Support poison as last resort & $4 \%$ & $4 \%$ & $4 \%$ & $p=0.811$ & $5 \%$ & $3 \%$ & $p=0.138$ \\
\hline $\begin{array}{l}\text { Prefer poison over other } \\
\text { control methods }\end{array}$ & $0.2 \%$ & $0 \%$ & $0.4 \%$ & $p=0.310$ & $0.1 \%$ & $0.3 \%$ & $p=0.673$ \\
\hline
\end{tabular}

Percentages represent the proportion of responses from a respondent subgroup in which a particular theme occurred.

theme occurred in $36 \%$ of responses from respondents living in counties with wild pigs and $31 \%$ of responses from respondents living in counties with no wild pigs (chi-square: $\mathrm{p}=0.150$ ). By comparison, the proportion of responses in which concerns were raised about poison constituting cruelty to wild pigs ranged from $11 \%$ (rural respondents) to $13 \%$ (respondents from counties with wild pigs), and the 
proportion of responses in which concerns were raised about impacts on humans were the same across all four subgroups at $7 \%$.

\section{Discussion}

When it comes to methods for controlling invasive species, the use of toxicants or other chemicals have often been found to have the lowest level of public support (e.g., Barr et al. 2002; Sheail 2003; Fraser 2006; Bremner and Park 2007). Our findings are consistent with these past studies. In particular, when we asked respondents about the ethicality of six different methods for controlling wild pigs, the only method that a majority (albeit a small majority at $51 \%$ ) found to be unethical was the use of a toxicant - even though we specified that it would cause minimal suffering and little harm to other wildlife. While one might reasonably hypothesize that individuals who live in counties where wild pigs are present would be more accepting of a toxicant than those who live in counties where the species is not yet present, our findings did not support this hypothesis. We found no significant difference in ethical attitudes towards wild pig toxicants between respondents from counties where wild pigs are present and counties where they are absent, nor did we find a significant difference in ethical attitudes towards wild pig toxicants between rural and urban county respondents. More surprising, the four subgroups shared the same concerns about toxicants in roughly equal measure - i.e., the proportion of responses to the open-ended question in which a particular theme occurred was remarkably similar across all four subgroups. In this regard, concern over possible impacts to non-target species was far and away the most common theme in respondents' answers, with approximately one-third of respondents from each of the four subgroups citing this concern.

We also note that although the highest percentage of respondents (67\%) agreed with the statement 'Trapping and removing wild pigs is ethical,' some respondents may have interpreted the statement to refer to nonlethal removal (e.g., a release of the animal elsewhere) though it is generally understood among wildlife professionals to entail the killing of an animal. This is supported by our finding that when the word 'lethally' was included in the same statement to modify the word 'removing,' the percentage of agreement fell by 15 percentage points (52\%), a statistically significant difference. This suggests that survey questionnaires and communications with the public should avoid the euphemistic term 'remove' in favor of clearer, more commonly understood terminology to avoid misunderstanding.
Indeed, the avoidance of misunderstanding was our rationale for using the term "poison" instead of "toxicant" in the questionnaire, though we acknowledge that the term "poison" may carry a more negative connotation that could have introduced some bias in the results. In addition, although only $20 \%$ of respondents disagreed with the statement "hunting wild pigs with dogs is ethical," some respondents may not have understood that this practice may involve using dogs to bite and restrain the pig, thereby placing the dog at risk of injury. The foregoing illustrates the challenges we faced in wording the questions clearly and concisely while at the same time striving to maintain comprehensibility and minimize bias and measurement error.

\section{Management implications}

As far as we are aware, this survey marks the first attempt to measure ethical attitudes across the entire United States towards wild pig toxicants and the management of wild pigs. Our findings offer useful insights for policy makers, toxicant developers, and resource managers. For one, responses to the six belief statements indicate that in rural and urban counties alike, a majority of the public is likely to accept or at least be open to considering most forms of lethal wild pig control. Indeed, more than half of all respondents agreed that hunting wild pigs without the use of dogs and trapping and lethally removing wild pigs are ethical practices. Moreover, while a slim majority of respondents registered ethical objections to toxicants, this does not necessarily mean that a safe and humane toxicant cannot gain the acceptance of most members of the public. It does, however, suggest there is a substantial burden on resource managers and toxicant developers to understand and address the public's concerns and to clearly communicate the need for the toxicant in a way that will resonate with those who have reservations or moral objections. In regards to individuals who have moral objections, Haidt (2001) suggested that it may be productive to communicate information in a manner that triggers a competing moral intuition, such that an individual comes to see an issue from more than one side. In such instances, the individual may go with the stronger intuition or use reasoning to choose among alternatives (Haidt 2001). In communicating the need for a wild pig toxicant, a competing moral intuition or belief might be triggered by, for example, describing the negative impact that non-native wild pigs have on the survival of native wildlife and the inadequacy of efforts to control wild pigs by other methods. Articulating the need in this manner could pit intuitions about the unethicality of toxicants against 
intuitions or beliefs about the importance of protecting native wildlife and habitat.

Our findings in connection with the open-ended question about toxicant usage also provide information that can inform toxicant development and public outreach efforts - particularly insofar as they suggest that the various segments of the public we studied share similar concerns. Given the large number of respondents who registered concern over potential impacts on non-target animals, as well as pain and suffering on the part of wild pigs, it is important that any wild pig toxicant and delivery system be as species specific as possible and result in a humane (i.e., relatively quick and painless) death for wild pigs. And while concern about the tainting of wild pig meat intended for human consumption ranked relatively lower among respondents' concerns in our study, it could easily become a contentious and litigated issue in any state where wild pigs are commonly harvested for consumption or are processed and sold to the public, as in Texas.

Public engagement and transparency can also aid in building the public's trust in resource managers and in demonstrating credibility (Genovesi et al. 2008), which is essential to initiatives involving the use of a toxicant. Research indicates that the public's perception and evaluation of information (e.g., information about the safety of a toxicant) is connected to their level of trust in the institution that provides the information. In this regard, general skepticism and distrust in science, government, and industry were apparent in a number of responses to our open-ended survey question concerning the use of a wild pig toxicant (e.g., 'There are always unintended consequences,' 'Seems it would be hard to prove poison causes minimal suffering and little harm to other wildlife,' and 'Despite industry and government assurances, poison don't [sic] always only impact the targeted species, Ex: DDT, neonicotinoids, etc., etc.'). Despite the much-discussed decline in the public's trust in science (Achterberg et al. 2017), scientific study and publications still appear to hold currency with the public when it comes to the safety of a toxicant. In the recent controversy over Kaput in Texas, lobbying efforts by opponents capitalized on the fact that there were no independent peer-reviewed publications concerning the toxicant's safety at that time (Crum 2017), and the Texas House of Representatives passed a bill requiring scientific study of any wild pig toxicant before it could be used in the state. Of course, no amount of scientific study or public engagement will likely ever eliminate all opposition to a toxicant in a pluralistic society, but providing credible information and allowing stakeholders to be heard may be critical to the perceived legitimacy and ultimate acceptance of any management action.

\section{Future research}

We recognize that attitudes towards invasive species management and the use of toxicants may vary significantly from state-to-state or within a state. A weakness of this research is that there were not enough respondents from any state to allow for generalization at the state level. Additional attitudinal studies at the state or local level - including indepth case studies - would be extremely valuable for purposes of informing state and local decisionmaking and developing more nuanced theory about the factors that affect or mediate attitudes, preferences, and concerns with respect to toxicants. We also echo Bremner and Park (2007) and Beasley et al. (2018) in calling for research that examines the effectiveness of different forms of public education campaigns related to invasive species management, including the ways in which different types of information influence attitudes. More generally, we call attention to the critical need for more research into human dimensions of invasive species. While much of the research concerning invasive species problems has focused on biological and ecological characteristics of the relevant species (McNeely 2001), such problems cannot be resolved without better understanding of the human behaviors that create or contribute to the problem and the factors that are critical to the public's support of management actions.

\section{Acknowledgements}

We are grateful to the USDA National Feral Swine Damage Management Program for funding this research. We wish to thank Jessica Tegt at Mississippi State University for assistance with our survey and the many individuals who participated in this research and made this study possible. We also thank the two anonymous reviewers for their constructive comments. Finally, we acknowledge and thank the individuals at the National Wildlife Research Center (USDA APHIS) who assisted with various phases of this study, including Julie Elser, Karina Ernst, Samantha DeGroot, Jordan Navin, and Ryan Levitt. Mention of commercial products does not represent an endorsement by the U.S. government.

\section{Disclosure statement}

No potential conflict of interest was reported by the author(s).

\section{Data availability}

Participants of this study did not agree for their data to be shared publicly, so supporting data are not available. 


\section{Disclaimer}

The findings and conclusions in this publication are those of the authors and should not be construed to represent any official USDA or U.S. Government determination or policy.

\section{References}

Achterberg P, de Koster W, van der Waal J. 2017. A science confidence gap: education, trust in scientific methods, and trust in scientific institutions in the United States, 2014. Public Underst Sci. 26(6):704-720.

Anderson A, Slootmaker C, Harper EE, Holderieath J, Shwiff SA. 2016. Economic estimates of feral swine damage and control in 11 US states. Crop Prot. 89: 89-94.

Barr, JJF, Lurz, PWW, Shirley, MDF, Rushton, SP. 2002. Evaluation of immunocontraception as a publicly acceptable form of vertebrate pest species control: the introduced grey squirrel in Britain as an example. Env Mgmt. 30(3):342-351.

Bartlett JE, Kotrlik JW, Higgins CC. 2001. Organizational research: determining appropriate sample size in survey research. Information Technol Learn Performance J 19: 43-50.

Beasley JC, Ditchkoff SS, Mayer JJ, Smith MD, Vercauteren KC. 2018. Research priorities for managing invasive wild pigs in North America. J Wild Mgmt. 82(4):674-681.

Bremner A, Park K. 2007. Public attitudes to the management of invasive non-native species in Scotland. Biol Conserv. 139(3-4):306-314.

Bridge PD, Sawilowsky SS. 1999. Increasing physicians' awareness of the impact of statistics on research outcomes: Comparative power of the t-test and Wilcoxon Rank-Sum Test in small samples applied research. J Clin Epidemiol. 52(3):229-235.

Caplenor CA, Poudyal NC, Muller LI, Yoest C. 2017. Assessing landowners' attitudes toward wild hogs and support for control options. J Environ Manage. 201: 45-51.

Cochran WG. 1977. Sampling techniques (3rd ed.). New York, NY: John Wiley \& Sons.

Corn JL, Jordan TR. 2017. Development of the national feral swine map, 1982-2016. Wildl Soc Bull. 41(4): 758-763.

Crum B. 2017. Special report: is poison the answer to feral hog problem? Abilene Reporter-News. https://www. reporternews.com/story/news/local/2017/03/04/poisonanswer-feral-hog-problem/98705028/. [verified November 2018].

Dillman DA, Smyth JD, Christian LM. 2014. Internet, phone, mail, and mixed-mode surveys. The tailored design method (4th ed.). Hoboken, NJ: John Wiley \& Sons.

Fraser A. 2006. 'Public Attitudes to Pest Control: A Literature Review.' (Department of Conservation, Wellington, New Zealand). https://www.doc.govt.nz/ Documents/science-and-technical/drds227.pdf. [verified December 2019]

Genovesi P, 2008. Limits and potentialities of eradication as a tool for addressing biological invasions. In:
Caldwell MM, Heldmaier G, Jackson RB, Lange OL, Mooney HA, Schulze ED, Sommer U, editors. Ecological studies. New York, NY: Springer. Vol. 193; p. 385-402.

Haidt J. 2001. The emotional dog and its rational tail: A social intuitionist approach to moral judgment. Psychol Rev. 108(4):814-834.

Harper EE, Miller CA, Vaske JJ, Mengak MT, Bruno S. 2016. Stakeholder attitudes and beliefs toward wild pigs in Georgia and Illinois. Wildl Soc Bull. 40(2):269-273.

Keiter DA, Mayer JJ, Beasley JC. 2016. What is in a 'common' name? A call for consistent terminology for nonnative Sus scrofa. Wildl Soc Bull. 40(2):384-387.

Lutman MW. 2017. Dataset: Feral Swine Presence. U.S. Department of Agriculture, Animal and Plant Health Inspection Service. Wildlife Services. National Wildlife Research Center, Fort Collins, CO.

McNeely JA. 2001. An introduction to the human dimensions of invasive alien species. In: McNeely JA, editor. The great reshuffling: Human dimensions of invasive alien species. Gland, Switzerland: IUCN; p. 5-22.

Neuendorf KA. 2002. The content analysis guidebook. Thousand Oaks, CA: Sage Publications, Inc.

Pimentel D. 2007. Environmental and economic costs of vertebrate species invasions into the United States. Managing Vertebrate Invasive Species 38. http://digitalcommons.unl.edu/nwrcinvasive/38. [verified November 2018].

Poché RM, Poché D, Franckowiak G, Somers D, Briley L, Tseveenjav B, Polyakova L. 2018. Field evaluation of low-dose warfarin baits to control wild pigs (Sus scrofa) in North Texas. PLoS One. 13(11):e0206070.. [verified December 2019].

R Development Core Team. 2018. R: A language and environment for statistical computing. Vienna, Austria: R Foundation for Statistical Computing.

Sheail J. 2003. Government and the management of an alien pest species: a British perspective. Landscape Res. 28(1):101-111.

Sjöberg L. 2008. Genetically modified food in the eyes of the public and experts. Risk Manag. 10(3):168-193.

Snow NP, Foster JA, VanNatta EH, Horak KE, Humphrys ST, Staples LD, Hewitt DG, Vercauteren KC. 2018. Potential secondary poisoning risks to non-targets from a sodium nitrite toxic bait for invasive wild pigs. Pest Manag Sci. 74(1):181-188.

Snow, NP, Jarzyna, MA, Vercauteren, KC. 2017. Interpreting and predicting the spread of invasive wild pigs. J Applied Ecol. 54:2022-2032.

Tanaka Y. 2004. Major psychological factors affecting acceptance of gene-recombination technology. Risk Anal. 24(6):1575-1583.

U.S. Census Bureau. 2010. 2010 Census Urban and Rural Classification and Urban Area Criteria. https://www. census.gov/geo/reference/ua/urban-rural-2010.html. [verified November 2018].

U.S. Census Bureau. 2017. Quick Facts. https://www.census.gov/quickfacts/fact/table/US/PST045217. [verified November 2018].

Vänninen I, Siipi H, Keskitalo M, Erkkilä M. 2009. Ethical compatibility of GM crops with intrinsic and extrinsic values of farmers: A review. TOJ. 3(3): 104-117. 